\title{
Towards a Patent Pool for HIV Medicines: The Background
}

\author{
Michelle Childs*
}

Campaign for Access to Essential Medicines, Médecins Sans Frontières, Rue de Lausanne 78, P.O. Box 116, CH-1211, Geneva 21, Switzerland

\begin{abstract}
Recent WHO guidelines for antiretroviral therapy recommend switching to less toxic, but more expensive medicines for first-line and second-line ART, raising questions about the financial sustainability of many AIDS treatment programmes. At the same time, many key generic producing countries such as India now grant pharmaceutical product patents so competition between multiple manufacturers will not be able to play the role it has in bringing down the price of newer drugs.
\end{abstract}

Overcoming these patent barriers will require a range of solutions, such as restricting patentability criteria, or compulsory licensing. One additional systematic solution is provided by the patent pool, a collective solution to the management of patent rights, initially presented by Médecins Sans Frontières to the French Foreign Ministry and subsequently the UNITAID Executive Board in 2006.

A patent pool must not be implemented at any costs, but answer medical needs, be based on economic realities and meet the access needs of the developing world, including middle-income countries.

\section{INTRODUCTION}

There have been striking advances in the past years in providing antiretroviral therapy (ART) in developing countries with an estimated three million people on treatment today [1]. Médecins Sans Frontières (MSF) provides antiretroviral (ARV) treatment to over 140,000 people in over 30 countries. 10,000 of them are children under five years of age.

Two key factors combine to make this possible. Firstly, the price of the first-line drug combination that is most commonly used in the developing world dropped, from US $\$ 12,000$ per patient per year in 2000 to less than US\$ 90 , thanks to fierce competition among multiple generic manufacturers in key producing countries like India [2]. Second, the creation by generic producers of a triple fixed-dose combinations (FDCs) of stavudine/lamivudine/nevirapine, made it possible for a person on ART to only have to take two pills a day. Simplifcation and reduced pill burden have been important factors to ensure treatment adherence and facilitate scale up in resource poor settings.

\section{HISTORY REPEATING? THE NEW ACCESS CRISIS}

But the access to medicines crisis is far from resolved. Not only do many still not receive access to treatment but also the per-patient cost of antiretroviral drugs is set to rise again. From 2005, a number of developments in the worlds of AIDS treatment and intellectual property has raised once more the spectre of price barriers and availability issues. *Address correspondence to this author at the Campaign for Access to Essential
Medicines, Médecins Sans Frontières, Rue de Lausanne 78, P.O Box 116, CH-
1211, Geneva 21, Switzerland; Tel: + 4122849 8405; Fax:+41 22849 8404;
michelle.childs@msf.org
Since 2006, the World Health Organization (WHO) recommendations includes tenofovir disoproxil fumarate (TDF) based first line regimens [3]. The significant side effects associated with stavudine (d4T) mean that it is preferable to move towards to less toxic regimens containing zidovudine (AZT) or TDF. In an MSF AIDS projects in Rwanda, almost one in every six people on stavudine had to change their regimen due to toxicity. Yet implementation has been slow as the price of the TDF-based regimens can be between four and as much as eleven times higher than the older, d4T-based regimens.

People on ART also require continuous access to different and newer medicine combinations as their treatment progresses. As some people in developing countries have now been on treatment for nine years or more, levels of resistance are increasing. More and more patients will thus need to switch regimens and have access to newer medicines, and will continue to do so for the duration of their lives. In MSF's longest-running AIDS project in Khayelitsha, South Africa, approximately 16 per cent of patients on treatment for five years needed to be switched to a second-line drug combination (MSF internal data, Khayelitsha Project, Cape Town, South Africa van Cutsem).

But the price of these second-line medicines is dramatically higher than the cost of the older ones. In some countries switching a patient from a first- to second-line regimen increases the cost of treatment between nine and seventeen-fold [2].

Finally, the intellectual property environment is changing. Before 2005, production by multiple manufacturers, the catalyst for the 99 per cent price drop for older antiretrovirals, was possible due to the lack of patents in manufacturing countries like India. This also allowed 
the production of fixed-dose combination pills - crucial to the simplification of treatment that has fostered global scale-up because patents on the individual compounds did not stand in the way of combining the drugs. But since India began granting pharmaceutical product patents in 2005, this situation is changing [4].

Now the patenting of newer medicines in India means that generic manufacturers are unlikely to be able to enter the market and create the kind of competition that leads to the dramatic price reductions seen in the past. India's new patent law contains valuable public health safeguards that limit patentability of drugs and allow civil society organisations to oppose patents before or after they are granted. Nevertheless, many of the newer ARVs will be patentable in India, and several, such as raltegravir, maraviroc or etravirine already are.

Against this changing situation, MSF and other treatment providers are once again faced with a situation where drugs could be priced outside the reach of patients.

\section{LOOKING FOR SOLUTIONS}

Overcoming these patent barriers will require a range of different solutions.

The restricting of patentability criteria - such as section $3 \mathrm{~d}$ and its public health safeguards contained in India's 2005 Patents Act - is an essential tool to keep the door open for generic competition.

Once drugs are patented, however, the only way to overcome monopoly control is through some kind of licensing. This means that generic manufacturers will no longer be able to produce affordable versions of drugs unless the company agrees to voluntary licences with generic manufacturers, or a government decides to overcome a patent barrier with a legal mechanism in patent law called a 'compulsory licence' (CL).

CLs have proven to bring down the price of drugs dramatically - the CL issued by Thailand for lopinavir/ritonavir (LPV/r) in January 2007 is perhaps the most clear illustration of this. Over the course of the past two years, the priced for LPV/r in middle-income countries has decreased by as much as 79 per cent from US\$2,200 per patient per year to as low as US\$470 in countries included in the Clinton Foundation consortium.

Although issuing a CL is entirely within World Trade Organization rules, countries that take the step typically face immense direct and indirect retaliatory measures and pressure from developing country governments and the pharmaceutical industry.

Yet the fight for greater access to essential drugs cannot sustainably be fought on a drug-by-drug, country-by-country basis alone. We still lack a systematic solution to the problem of access to medicines for developing countries.

In 2006, a new drug purchasing facility for HIV, TB and malaria, UNITAID was being developed under French impetus. Given the new body's focus on providing innovative solutions, MSF identified this move as a potential opportunity to promote new ways to overcome access and innovation barriers for HIV medicines.

\section{A COLLECTIVE SOLUTION TO THE MANAGE- MENT OF PATENT RIGHTS}

In June 2006, MSF submitted two papers to the French Ministry of Foreign Affairs and UNITAID on intellectual property rights and medicines procurement (Paper one: Government use for non-commercial purposes, nonrecognition and non- enforceability of pharmaceutical patent and data protection. Paper two: Patent Pools).

The first recommended that UNITAID require the purchase of ARVs from the lowest-cost quality-assured providers and actively encourage its beneficiaries to use the provisions of the Doha Declaration on TRIPS and Public Health to allow for the purchase of generic ARVs when a patent exists.

The second paper, prepared with input from Essential Inventions, now part of Knowledge Ecology International, outlined the case for UNITAID to establish a patent pool for HIV medicines (Declaration of Interest: the writer was at that time CEO of Essential Inventions and worked with MSF on the preparation of the two papers). Such a move would complement existing efforts to lower drug prices and offer a more systematic approach to the collective management of patent rights.

In a patent pool, the holders of individual drug patents (such as companies, universities or research institutes) put their patents into a 'pool.' The administrators of the pool then license the use of the patents to any interested producers for production or further development, on payment of a royalty, which goes back to the original patent holder.

There were a number of potential models for such a pool. One of the most developed at the time was the proposal for a pool for essential medicines presented to WHO, UNAIDS and the Global Fund to Fight AIDS, Tuberculosis and Malaria by Essential Inventions on 17 January 2005 [5], which in turn drew on the US experience of the Manufacturers Aircraft Association pool, formed in 1917 in response to a crisis: the US decision to enter World War I.

The proposal for the creation of a UNITAID Medicines patent pool was spurred by a similar crisis: the looming crisis in innovation of and access to HIV medicines in developing countries.

The initial MSF proposal suggested that the pool focus on the patents required for the development and production of generic fixed-dose combinations of $\mathrm{TDF} / 3 \mathrm{TC} / \mathrm{EFV}$ or NVP both for adult use and for use in children, and the development of generic versions of heat-stable LPV/r.

The pool needed to recognise the economic realities of generic production and the geographic scope of the licences would have to be sufficiently large to ensure generic manufacturers could benefit from economies of scale and be able to export. MSF also recommended that the initial aim of the pool should be to seek voluntary contribution of patents by patent holders, but that compulsory licensing should never be ruled out if this approach failed. 
The pool model was seen as having the potential to accelerate access to more affordable medicines, as the development of generic medicines could start well before a 20-year patent term expires. A pool would also help to stimulate the development of new FDCs and paediatric formulations. By reducing both risks and transaction costs, it also offers an attractive alternative to the current system for both patent-holders and medicines producers. All of these factors combined can translate into important benefits for patients through wider access to affordable, appropriate medicines.

\section{THE ROAD TO THE POOL}

The French Ministry of Foreign Affairs suggested that MSF present at the UNITAID Board meeting in September 2006. The Board felt it was worth further exploration and an independent legal review of the proposal was commissioned. Its conclusion that the concept was in principle legally viable was reported back to the Board in July 2007.

The UNITAID board recognised that the key issues would in practice be economic and political - in other words, the willingness of patent holders to contribute to the pool, and defining the nature of the incentives that would be required for them to do so. Very quickly, the discussions focused on two key areas:

- $\quad$ the nature of the pool - what medicines should be included; and

- $\quad$ the scope of the pool. Here, there were two aspects: firstly, determining which countries can manufacture medicines under licence to the pool and secondly, determining in which countries such medicines could be sold. The question arose as to whether the pool should be restricted to low income countries only, as the inclusion of middle-income countries was and remains the most contentious issue. On the one hand, these are countries whose actual or potential manufacturing capability (in addition to the large number of potential beneficiaries of more affordable medicines) makes it essential for them to be included in the pool. On the other, these are precisely the countries where originator companies in the mediumterm foresee strong market growth and therefore there was a concern that they may be unwilling to put patents in the pool without strong incentives to do so.

In December 2007, the UNITAID Board agreed to continue to explore the option of establishing a pool, requesting the Secretariat to establish and lead a multidisciplinary team of experts to propose options for the key characteristics of the pool, including its nature and scope. MSF was invited to be part of this Expert Group. There were a number of meetings of the Group in 2008, with interim reports to the UNITAID Board.

In July 2008, the UNITAID Board was asked to endorse the principle of the establishment of a patent pool, based on a report drawn up by the UNITAID Secretariat, and drawing on discussions with the Expert Group [6]. The Secretariat recommended that:
- $\quad$ the UNITAID patent pool be set up as a voluntary mechanism.

- $\quad$ the coverage of the patent pool should not be limited to patents relating to FDCs of ARVs for adult and paediatric use, but rather should provide the opportunity for the patent owners to voluntarily licence any patents useful in providing ARV therapy to address low- and middle-income country needs.

- at least in its initial phases, the scope of the patent pool should include all middle- and lower-income countries (i.e. those countries that are not defined as high-income by the World Bank), subject to the ability of patent owners to make exceptions for all countries where they do not want the licence to apply. On the basis that this provided maximum flexibility without unnecessarily narrowing the scope of the coverage.

The UNITAID Board gave approval in principle and mandated the establishment of a task force to design the structure for the medicines patent pool and develop the tools necessary to implement it, and to report back to the Board for final approval.

\section{CONCLUSION: A POOL, BUT NOT AT ANY COST}

The UNITAID Board, made up of developing and developed country representatives, had shown great vision in agreeing to the patent pool in principle, publicly acknowledging that new solutions are needed to ensure that access targets can be met.

However this decision is rather like receiving the planning permission to build a house: the pool must now be built. We are at the beginning of the process, not the end.

Because the pool is voluntary, its success will depend on patent owners - be they pharmaceutical companies, universities or researchers - putting their patent into a pool, and for generic companies to access the pool, in return for payment of a fair royalty rate.

There may be difficult discussions ahead, which will require all involved to keep a focus on the issue at stake: the entirely predictable problem in the short-term of rising drug prices, putting access to medicines at risk. There is an opportunity to act now, and avoid confrontation and litigation which costs time and lives.

A pool should not be implemented at any cost, however. It must be based on three criteria:

1) Medical needs: these go beyond just first- and second-line drugs. Newer drugs, such as raltegravir, etravirine and darunavir, are potent, safe and are now well known and part of treatment recommendations in developed countries. Other new medicines, still in development, such as rilpivirine, have the potential to be co-formulated, low dose and cheap and can be used either in treatment-experienced or naïve patients. Also, new booster medicines such as GS-9350 and SPI-452 are needed to avoid the current one company monopoly on ritonavir. The wide time gap in accessing these medicines in resource limited settings 
should be avoided. These medicines can save lives of patients who have been exposed to all existing WHO treatment lines, but can also be the cornerstone of innovative first line regimens. Concerning paediatric HIV medicines, we would like to have all medicines already tested in children included, namely, darunavir, atazanavir, fosamprenavir and paediatric heat-stable ritonavir and the newer ARV's tested and developed for paediatric indications for all ages [7].

2) Economic realities: licences must include all developing countries. The UNITAID proposal is for all developing countries, whether least-developed or middle-income. This is an important point. It is primarily middle-income countries that have generic production capacities. In addition, if the licences are made applicable to a large market in the developing world, production would be economically attractive to multiple producers. Competition between multiple producers would bring down drug prices which in turn would help to reach greater numbers of patients.

3) Meet the access needs in all developing countries. All developing countries should be able to benefit from the medicines produced under licence from the UNITAID pool. Within middle-income countries, wide differences in income levels persist, and there are poor populations that need access to more affordable medicines too, as the recent example of Thailand has shown.
If the UNITAID patent pool succeeds, the effects could be very significant, both in the area of access to medicine, namely bringing prices down, and in the area of developing desperately needed drug combinations and paediatric formulations. But success will depend on everybody working together to build the pool.

That is the challenge for all of us.

\section{REFERENCES}

[1] Towards Universal Access; Scaling up Priority HIV/AIDS Interventions in the Health Sector. Progress report 2008. WHO, UNAIDS, Unicef. WHO 2008. Available from: www.who.int/ hiv/pub/meetingreports/Second_Line_Antiretroviral.pdf [Accessed: July 2009].

[2] Untangling the Web of Antiretroviral Prices, 11th edition, July 2008. Médecins Sans Frontières - Campaign for Access to Essential Medicines - Available from: www.msfaccess.org [Accessed: July 2009].

[3] Antiretroviral Therapy for HIV Infection in Adults and Adolescents: Recommendations for a public health approach, 2006 Revision, WHO. Available from: www.who.int/hiv/pub/guidelines/ artadultguidelines.pdf [Accessed: July 2009].

[4] 't Hoen E. The global politics of pharmaceutical monopoly power. Amsterdam 2008; Available from: http://www.msfaccess.org/ [Accessed: July 2009].

[5] Proposal for Patent Pool for Essential Medicines (PPEM), Addis Ababa, 3rd March 2005. Available from: http://www.essentialin ventions.org/docs/eppa/ [Accessed: July 2009].

[6] UNITAID Executive Board, 8th Session 2- 3 July 2008 - Geneva, Switzerland-Agenda item 11- update from the Secretariat on the patent pool. Available from: http://www.unitaid.eu/ [Accessed: August 2009].

[7] MSF statement at the $17^{\text {th }}$ WHO Expert Committee on the Selection and Use of Essential Medicines, 23 March 2009. Available from: http://www.msfaccess.org [Accessed: July 2009].

This is an open access article licensed under the terms of the Creative Commons Attribution Non-Commercial License (http://creativecommons.org/licenses/by-nc/ 3.0/) which permits unrestricted, non-commercial use, distribution and reproduction in any medium, provided the work is properly cited. 